\title{
Injecting drug users in India: Understanding sexual behaviours and sexual networks to design effective behaviour change strategies
}

\author{
Avina Sarna \\ Population Council \\ Waimar Tun \\ Population Council \\ Aruna Bhattacharya \\ Population Council \\ Vaishali Sharma Mahendra \\ Neville Selhore
}

See next page for additional authors

Follow this and additional works at: https://knowledgecommons.popcouncil.org/departments_sbsr-hiv

Part of the Demography, Population, and Ecology Commons, Family, Life Course, and Society Commons, International Public Health Commons, Medicine and Health Commons, and the Substance Abuse and Addiction Commons

How does access to this work benefit you? Let us know!

\section{Recommended Citation}

Sarna, Avina, Waimar Tun, Aruna Bhattacharya, Vaishali Sharma Mahendra, Neville Selhore, Arjun Singh, and Louis Apicella. 2007. "Injecting drug users in India: Understanding sexual behaviours and sexual networks to design effective behaviour change strategies," Research update. New Delhi: Population Council. 


\section{Authors}

Avina Sarna, Waimar Tun, Aruna Bhattacharya, Vaishali Sharma Mahendra, Neville Selhore, Arjun Singh, and Louis Apicella 

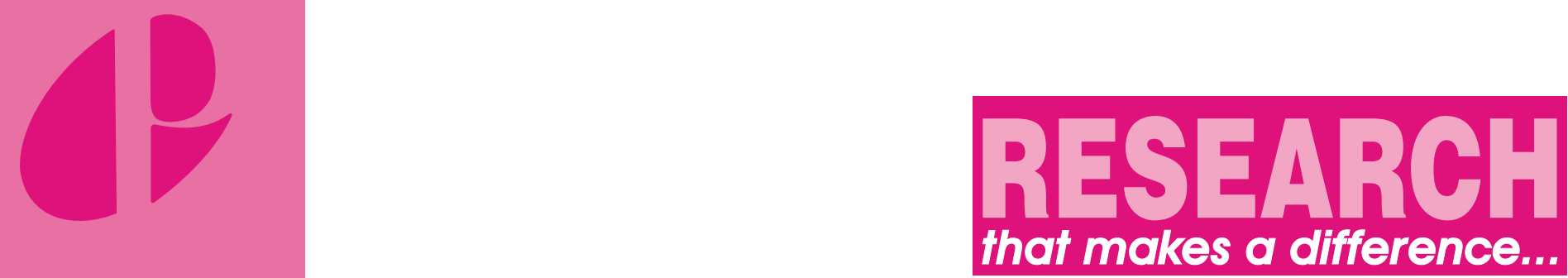

\section{INJECTING DRUG USERS IN INDIA: Understanding Sexual Behaviours and Sexual Networks to Design Effective Behaviour Change Strategies}

\section{Background}

The practice of injecting drug use has been spreading to different parts of India since the early 1980s. Associated with this spread has been an increase in HIV prevalence rates in injecting drug user (IDU) populations. ${ }^{(1,2)}$ IDUs engage in both risky injection and sexual practices that increase the risk for HIV transmission. ${ }^{(3,4)}$ While risky injection practices are well understood, there is limited understanding of IDUs' sexual behaviours and social networks. This information is extremely important as IDUs can act as a bridge for transmission of HIV infection to non-injecting and non-drug using partners. The Population Council conducted a study to explore patterns of risky sexual behaviours, sexual network characteristics, and drivers of high-risk behaviours of IDUs in Delhi and Imphal.

\section{Study Methodology}

Sites: The study was undertaken in two cities, Imphal and Delhi, in one high and one low HIV prevalence state in India, Manipur and Delhi, respectively. The contrasting settings were selected to allow for differences in social and behavioural characteristics that influence the HIV epidemic in this population to be explored. Study sites were purposively selected based on existing harm reduction programmes and IDU networks in these cities. One non-governmental organisation in each city served as the study partner for this research: Sahara in Delhi and SASO in Imphal.

Study design: Researchers from the Population Council conducted a cross-sectional study with current IDUs between September and December 2006. Current IDUs, who had used nonprescription intravenous drugs in the past six months and were over 16 years of age, were interviewed about drug use and injecting behaviours, knowledge of HIV/AIDS, sexual behaviours, and sexual networks, including detailed information about their sex partners.

A total of 1600 current IDUs (800 in Delhi; 800 in Imphal) were recruited into the study using Respondent Driven Sampling (RDS). The RDS method, whereby study participants are asked to recruit their IDU peers, is used in research with hard-to-reach or hidden populations such as IDUs, and it provides estimates that can be generalizable to the larger reference population of IDUs in the respective cities.

Respondents were asked about their sexual activity, which was defined as having sexual intercourse (vaginal or anal) in the past 12 months, with regular, commercial/sex worker, and non-regular sex partners. A regular partner was defined as a spouse or a live-in partner. A commercial/sex worker partner was someone the respondent had sex with in exchange for money, gifts or drugs. A non-regular partner was defined as a partner the respondent was not living with and who was not a commercial partner. Information on condom use was elicited for each type of sex partner. Consistent condom use was defined as condoms used at every sexual act during the reporting reference period.

\section{Characteristics of IDU Population in Delhi and Imphal}

A total of 800 current IDUs were interviewed in each city, the vast majority of whom were males (783 in Delhi and 766 in Imphal). The median age for male and female IDUs was similar at both sites (30 years). Important differences were observed in education levels, living conditions, and marital and employment status of IDUs across the two sites. Almost half the male and more than three-fourths of female IDUs from Delhi reported no education. By contrast, three quarters of male and half of female IDUs from 


\section{INJECTING DRUG USERS IN INDIA: \\ Understanding Sexual Behaviours and Sexual Networks to Design Effective Behaviour Change Strategies}

Manipur reported at least 6 to 12 years of education. Additionally, male IDUs from Delhi represented a largely street-based $(68 \%)$ and single $(57 \%)$ population compared to respondents from Imphal, who reported living at home $(98 \%)$ and were more likely to be married or cohabiting (59\%). Female IDUs were mostly married (15/17) in Delhi and mostly widows $(15 / 34)$ in Imphal. The majority of male IDUs from Delhi were employed, primarily as rag pickers, while less than half the male IDUs from Imphal were employed. Almost all the female IDUs from Delhi were unemployed; one-third were unemployed in Imphal.

As there were few female IDUs in the study, this summary primarily focuses on findings from male IDUs.

\section{Key Findings}

\section{Distinctly different patterns of drug use observed in Delhi and Imphal}

IDUs in Delhi reported primarily injecting pharmaceutical agents such as buprenorphine $(93 \%)$, tranquilizers $(83 \%)$, and antihistamines and sedatives $(91 \%)$, while IDUs in Imphal primarily injected heroin (79\%). IDUs from Delhi reported multiple injections per day compared to those from Imphal ( $61 \%$ vs. $27 \%)$. Additionally, injecting drug use behaviours appear to be a more recent phenomenon in Delhi compared to Imphal. A quarter of the IDUs in Delhi $(26 \%)$ had been injecting for less than one year and a further 50 percent had been injecting for between 1-5 years. By contrast in Imphal, nearly 60 percent had been injecting for at least six years

\section{Needle sharing is commonly practiced}

A high proportion of IDUs in Delhi (41\%) and Imphal $(60 \%)$ reported sharing needles/syringes with others. IDUs from Imphal were more likely than those from Delhi to report high-risk injecting practices such as using a needle used by someone else ( $43 \%$ vs. $33 \%$ ); lending a needle to someone else after using it (50\% vs. $38 \%$ ); sharing injection equipment ( $71 \%$ vs. $28 \%)$ and drawing up drug solution from a common container (70\% vs. $55 \%)$.

\section{HIV, Hepatitis B and C related knowledge and testing very low}

More than a quarter of the IDUs in Delhi (26\%) had not heard of HIV/AIDS and only 37 percent of them had been tested for HIV infection. In Imphal although nearly all (98\%) had heard of HIV/AIDS only 49 percent had undergone testing, highlighting a gap in prevention programmes. Awareness of Hepatitis B and C was also extremely low among IDUs. Sixty-five percent of IDUs in Imphal and 14 percent in Delhi had heard of Hepatitis B and 46 percent and nine percent had heard of Hepatitis $C$ in the two cities, respectively. Of those who had heard of hepatitis, less than a third had been tested for these infections.

Sex with commercial partners common in Delhi, while regular partnerships were more the norm in Imphal

Sixty-four percent of male IDUs in Delhi and 54 percent in Imphal were sexually active in the last 12 months. While the majority of the sexually active male IDUs had sex with female partners in both Delhi (90\%) and Imphal (95\%), important differences in sexual behaviours were evident from the types of partners they reported. Over half of the IDUs in Delhi (58\%) who had sex with a female partner in the last 12 months, did so with a commercial partner whereas the majority (82\%) in Imphal did so with a regular partner.

About 20 percent of male IDUs in Delhi reported sex with male partners, the majority $(78 \%)$ of whom paid for sex with other men.

Condom use markedly low with all types of sex partners

Self-reported consistent condom use with regular partners in the last 12 months was extremely low in both Delhi $(8 \%)$ and Imphal (19\%). Although consistent condom use with commercial sex partners was higher than with regular and non-regular partners, it was still extremely low. [Figure 1]

Figure 1: Consistent condom use over the last 12 months with different types of sex partners among IDUs in Delhi and Imphal.

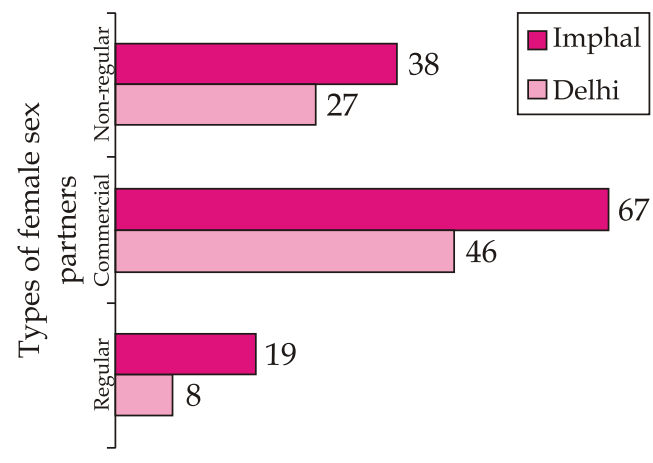

Percent

Delhi: regular partners $n=182$; commercial partners $n=293$; non-regular partners $n=66$ Imphal: regular partners $n=274$; commercial partners $n=57$; non-regular partners $n=66$ 
Multiple sex partnerships found to be prevalent Among sexually active male IDUs, multiple partnerships were common. In the previous 12 months, 38 percent of sexually active male IDUs in Delhi had 2-5 female sex partners and slightly over ten percent had more than six female partners. Although multiple partnerships were less common in Imphal, 21 percent of sexually active male IDUs reported having had at least 2 female sex partners in the last 12 months.

\section{Concurrent sex partnerships were found to be prevalent particularly among male IDUs in Delhi}

Concurrency has been shown to be an important factor in the spread of HIV. ${ }^{6}$ Among male IDUs who had more than one partner in the last 12 months (Delhi $n=196$; Imphal $n=116$ ), a substantial percentage (36\% in Delhi and $24 \%$ in Imphal) had concurrent partnerships, defined as sexual relationships that overlapped in time. Further, nearly half of the concurrent relationships in Delhi (46\%) and a third in Imphal (33\%) were unprotected, that is no condoms were used at last sex with any of the concurrent sexual partners.

\section{Risky patterns of sexual mixing observed} This study found sexual mixing patterns that can speed the spread of HIV and STIs beyond the high-risk group of IDUs. Five percent of male IDUs in Delhi and 12 percent in Imphal who had two or more partners in the last 12 months reported having at least one non-regular or commercial female partner in addition to a regular female partner. Sexual mixing across sexes and across age groups was also seen. A small subset of sexually active male IDUs in Delhi $(7 \%)$ engaged in sex with both male and female partners in the last 12 months. A moderate proportion of sex partners in Delhi $(27 \%)$ and Imphal (12\%) were at least 10 years younger than the respondents.

Another type of sexual mixing evident in both cities was that the majority of the male IDUs' sex partners were non-injecting partners, which has major implications for the spread of HIV. Ninety-seven percent of male IDUs who had regular female sex partners reported that their partners were non-injectors. Similarly, threequarters of male IDUs who had non-regular partners and two-thirds of those who had commercial sex partners reported that their partners were non-injectors. Such dissortative sexual mixing (i.e. ties between non-like groups) represents a higher-risk sexual behavioural pattern, as there is a potential to bridge between higher and lower risk groups.

\section{Program Implications and Recommendations}

The exploratory study, conducted in one high and one low HIV prevalence state, suggests that two distinctly different drug use patterns, living conditions and sexual risk behaviour are shaping the HIV epidemic in the two cities. These differences require a varied approach in addressing HIV-prevention in these two populations. Wider interventions to reach the unstable and homeless IDUs of Delhi and to retain them within targeted intervention programmes are needed, while interventions in Imphal must take into account that the target population is somewhat educated, married or co-habiting, and living in proper housing. Additionally, different counselling methods may be more effective for rehabilitation with recent injectors (e.g. IDUs in Delhi) versus longer term injectors who may have more severe addictions (e.g. IDUs in Imphal). Overall information, education and communication (IEC) should emphasize consistent use of sterile needles, proper cleaning and disposal techniques.

Sexual risk behaviours among IDUs with female partners suggest high rates of multiple partners, sex with commercial partners, low condom use with all types of partners and concurrent relationships. Male-to-male sex was characterized by multiple partners, high rate of partner change and very low condom use. IEC materials and prevention interventions needs to emphasize partner reduction and consistent condom use with all type of partners for all types of sex (vaginal, anal and oral).

Although the focus of targeted interventions has been HIV prevention, the study reveals that very few IDUs have been tested for HIV infection. This impedes prevention efforts and access to treatment and care for HIV positive IDUs. It is imperative that prevention programmes emphasize and facilitate HIV testing in this population. Additionally, given that Hepatitis B and C infections are common among IDUs, both of which impact the outcome of HIV infection and subsequent treatment with ART, IDU prevention efforts need to be widened to include testing for Hepatitis B and C and the provision of Hepatitis $B$ vaccination for IDUs.

Overall, a comprehensive prevention approach addressing risky injection practices with risky sexual behaviour that is tailored to the needs of different IDU populations is needed. A uniform

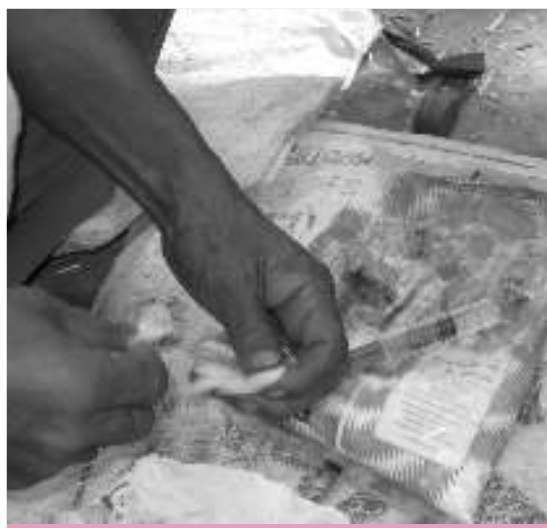


one-size-fits-all prevention programme may not be effective across the country. Similar research is recommended for other cities in India to explore differences in these behaviours that may require a different prevention approach.

\section{Proposed behaviour change communication strategies}

Behaviour change communication strategies outlined here are based on discussions with current IDUs, program managers and outreach workers. IDUs at both sites expressed a preference for face-to-face contact with health workers and peers for effective communication; therefore, increased interpersonal contact and outreach activity with IDU populations is recommended. Key messages should focus on increasing awareness of HIV in combination with reduction in risky sexual and injecting behaviours. A peer outreach programme with a focus on experience sharing and peer role modelling, using a cadre of peer educators (ex-
IDUs) who have undergone advanced training in communication methods is proposed.

Findings suggest a need for widening the focus of IEC materials and BCC activities from only providing information on transmission of HIV to an active process involving self risk assessment, a reduction in a misplaced sense of security of lack of risk, forming a link between the risks arising from unsafe injection practices to those arising from risky sexual behaviours and encouraging knowledge of HIV status. Life skills based activities and outreach to address decision making skills, ability to withstand peer pressure and purchasing, accessing and using condoms on a regular basis need to be emphasized.

Expanding awareness and prevention interventions to address secondary stakeholders such as law enforcement agencies, parents and policy makers are needed. Interventions targeting partners of IDUs, key stakeholders in HIV prevention, warrant consideration.
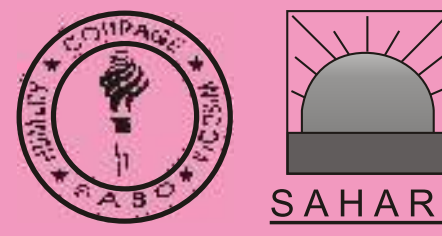

$\underline{\text { SAHARA }}$
For further information please contact:

Dr Avina Sarna

Population Council

53, Lodi Estate

New Delhi - 110 003, India

Tel: 91-11-2469 9747/48

Fax: 91-11-2461 0912

Email: info-india@popcouncil.org

\section{www.popcouncil.org}

\section{Contributors}

Avina Sarna, Waimar Tun,

Aruna Bhattacharya, Vaishali Mahendra, Neville Selhore, Arjun Singh and Louis Apicella.

Donor

Department for International Development, UK

\section{References:}

1. Dorabjee, J., and L. Samson. 2000. A multi-centre rapid assessment of injecting drug use in India. International Journal of Drug Policy, Vol. 1, No.11(1-2), pp.99-112.

2. Eicher, A.D., N. Crofts, S. Benjamin et al. 2000. A certain fate: Spread of HIV among young injecting drug users in Manipur, north-east India. AIDS Care. Vol.12 (4), pp.497-504.

3. Panda, S., A. Chatterjee, S. Bhattacharjee et al. 2000. Transmission of HIV from injecting drug users to their wives in India. International Journal of STD \& AIDS. Vol. 11(7), pp. 468-73.

4. Sarkar, S., S. Panda, K. Sarkar et al. 1995. A cross-sectional study on factors including HIV testing and counselling determining unsafe injecting practices among injecting drug users of Manipur. Indian Journal of Public Health, Vol.39 (3). pp. 86-92.

5. Heckathorn, D. 1997. Respondent-driven sampling: A new approach to the study of hidden populations. Social Problems. Vol. 44 (2), pp.174-99.

6. Morris, M. and M. Kretzschmar. 1991. Concurrent partnerships and the spread of HIV. AIDS, Vol. 11, pp. 641-48. 